\title{
Effect of surface treatment of graphene nanoplatelets for improvement of thermal and electrical properties of epoxy composites
}

\author{
Minjae Kim, Yeongseon Kim, Sung Hyeon Baeck and Sang Eun Shim \\ Department of Chemistry and Chemical Engineering, Inha University, Incheon 402-751, Korea
}

\section{Article Info}

Received 30 June 2014

Accepted 2 October 2014

*Corresponding Author

E-mail: seshim@inha.ac.kr Tel: $+82-32-860-7475$

\section{Open Access}

DOI: http://dx.doi.org/

10.5714/CL.2015.16.1.034

This is an Open Access article distributed under the terms of the Creative Commons Attribution Non-Commercial License (http://creativecommons.org/licenses/ by-nc/3.0/) which permits unrestricted non-commercial use, distribution, and reproduction in any medium, provided the original work is properly cited.

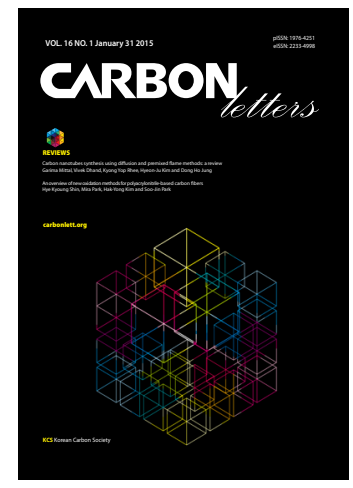

http://carbonlett.org

pISSN: 1976-4251

elSSN: 2233-4998

Copyright $\odot$ Korean Carbon Society

\begin{abstract}
In this study, in order to improve the thermal and electrical properties of epoxy/graphene nanoplatelets (GNPs), surface modifications of GNPs are conducted using silane coupling agents. Three silane coupling agents, i.e. 2-(3,4-epoxycyclohexyl)-ethyltrimethoxysilane (ETMOS), 3-glycidoxypropyltriethoxysilane (GPTS), and 3-glycidoxypropyltrimethoxysilane (GPTMS), were used. Among theses, GPTMS exhibits the best modification performance for fabricating GNP-incorporated epoxy composites. The effect of the silanization is evaluated using transmission electron microscopy (TEM), scanning electron microscopy, thermogravimetric analysis, and energy dispersive X-ray spectroscopy. The electrical and thermal conductivities are characterized. The epoxy/silanized GNPs exhibits higher thermal and electrical properties than the epoxy/raw GNPs due to the improved dispersion state of the GNPs in the epoxy matrix. The TEM microphotographs and Turbiscan data demonstrate that the silane molecules grafted onto the GNP surface improve the GNP dispersion in the epoxy.
\end{abstract}

Key words: graphene, epoxy, composite, surface treatment, thermal conductivity

\section{Introduction}

Recently, a large number of papers have been published in regard to thermally and electrically conductive polymer composites (CPCs). These CPCs have attracted significant attention due to their unique combination of metallic conductivity and polymeric properties [1]. For these reasons and more, CPCs are widely used as high strength composites, ultrasound transducers, electromagnetic shielding, electrically conductive, and thermal conductive materials [2-5].

Carbon materials such as carbon nanotubes (CNTs), graphite, carbon black, and graphene nanoplatelets (GNPs) have been used as fillers in order to provide electrical and thermal conductivity to polymer composites. Carbon materials are promising candidates for conductive fillers due to their distinctive structure and superior electrical and thermal properties. Graphite has a two-dimensional nanostructure; CNTs have a high aspect ratio; and carbon black has bulk electrical conductivity. Furthermore, they have superior electrical and thermal conductivity [6-8].

Among the carbon materials, GNPs have recently garnered a significant attention. GNPs are composed of a monolayer of carbon atoms, and these individual sheets have an sp2hybridzed carbon structure bound in two dimensions. This unique structure causes high thermal and electrical conductivity. For these reasons, GNPs are considered to be promising fillers that can increase the electrical and thermal properties of composites [9-11]. However, despite the superior intrinsic properties of GNPs, the thermal and electrical conductivity of the polymer/GNP composites are lower than expected [12,13]. One cause of this is the poor dispersity of GNPs in the polymeric matrix. 
In order to solve this problem, significant research efforts using surface modification have been undertaken [14]. Above all, Ma et al. [15] investigated the effect of surface modifications of CNTs using silane coupling agents. Their results demonstrated that grafting silane molecules on the CNT surface increased the dispersion of CNTs in epoxy matrices. Accordingly, the interfacial interactions between silane molecules on the modified CNT surface and the epoxy matrix increased the mechanical and thermal properties of the composites [16].

In general, surface modifications using strong acids result in effectively improved dispersion of carbon materials in the polymer matrix. However, this method causes the defects in the intrinsic structure of the carbon materials; thus, the thermal and electrical conductivity of epoxy composites filled with carbon materials that are modified by strong acids become poor [1719]. Unlike this method, surface modification of carbon materials using silane coupling agents (silanization) can minimize the defects of the carbon material structure [16]. Furthermore, this surface modification using silane coupling agents is implemented through a chemical reaction between the hydroxyl groups of the carbon materials and the trialkoxy groups of the silane coupling agents. In contrast, other functional groups of silane coupling agents such as amine, thiohydroxy, ethylene, epoxy, etc., can remain intact. Consequently, the interfacial interactions between the remaining functional groups of substrates and the polymer matrix cause increases in the dispersion of carbon materials [20-23].

In this work, the effect of the silanization of GNP surfaces is demonstrated on the electrical and thermal conductivity of the epoxy composites incorporated into raw and silanized GNPs. Prior to this silanization reaction, hydroxylation is performed under mild conditions. After the silanization, the epoxy/GNP composites are fabricated and their electrical and thermal conductivities are measured. Furthermore, in order to demonstrate the dispersity of the silanized GNP, i.e. the interfacial interaction between the GNP and epoxy matrix, transmission electron microscopy (TEM) and Turbiscan analyses are conducted.

\section{Experimental}

\subsection{Materials}

Tetrabutylammonium bromide (TBABr, 99\%) was purchased from Junsei Chemical (Japan). Hydrochloric acid ( $\mathrm{HCl}, 36 \%)$, potassium permanganate $\left(\mathrm{KMnO}_{4}, 99.3 \%\right)$, methanol, and methylene chloride $\left(\mathrm{CH}_{2} \mathrm{Cl}_{2}\right)$ were purchased from Samchun Chemical (South Korea). Epoxy resin (YD 128) and curing agent (HN 2000) were supplied by Kukdo Chemical (South Korea); these were based on diglycidyl ether derived from bisphenol-A and modified aromatic amine, respectively. The accelerator (2-ethyl-4-methyl-imidazole, 95\%) was supplied by Aldrich (USA). The GNPs (diameter: $5 \mu \mathrm{m}$, surface area: $100 \mathrm{~m}^{2} / \mathrm{g}$, and average thickness: $10 \mathrm{~nm}$ ) were provided by Cheap Tubes Inc. (USA). Finally, 2-(3,4-epoxycyclohexyl)-ethyltrimethoxysilane (ETMOS, KBM 303), 3-glycidoxypropyltriethoxysilane (GPTS, KBE 402), and 3-glycidoxypropyltrimethoxysilane (GPTMS, KBM 403) were purchased from Shin-Etsu Chemical Co., Ltd. (Japan). All chemicals were used without further purification.

\subsection{Hydroxylation of raw GNPs}

First, $1 \mathrm{~g}$ of raw GNP and $300 \mathrm{~mL}$ of $\mathrm{CH}_{2} \mathrm{Cl}_{2}$ were added into a $1000 \mathrm{~mL}$ beaker and the mixture was dispersed via ultrasonication (500 W, Materials \& Sonics Co., USA) for $30 \mathrm{~min}$. Then, $3 \mathrm{~g}$ of TBABr dissolved in $30 \mathrm{~mL}$ of deionized water, 30 $\mathrm{mL}$ of acetic acid, and a $\mathrm{KMnO}_{4}$ solution $\left(0.75 \mathrm{~g} \mathrm{KMnO}_{4}\right.$ dissolved in $20 \mathrm{~mL}$ deionized water) was added to the solution. The mixture was stirred continuously at $60^{\circ} \mathrm{C}$ for $24 \mathrm{~h}$. The mixture was washed with $\mathrm{HCl}$ and filtered with methanol through a Teflon filter with a $0.2 \mu \mathrm{m}$ pore size. The methanol-washing step was repeated for a minimum of five cycles. After washing, the filtered products were dried in a vacuum oven for $48 \mathrm{~h}$ at $60^{\circ} \mathrm{C}$. After drying, the hydroxylated GNPs were achieved.

\subsection{Silanization of the hydroxylated GNPs}

First, $1 \mathrm{~g}$ of hydroxylated GNPs and acetic acid solution $(5 \mathrm{~g}$ of acetic acid dissolved in $500 \mathrm{~g}$ of deionized water) were added into a $1000 \mathrm{~mL}$ beaker and the mixture was dispersed via ultrasonication for $30 \mathrm{~min}$. Then, $0.05 \mathrm{~g}$ of silane coupling agent (ETMOS, GPTS, or GPTMS) was added to the mixture, which was then stirred continuously at $25^{\circ} \mathrm{C}$ for $24 \mathrm{~h}$. The mixture was filtered with methanol through a cellulose filter with a $0.2 \mu \mathrm{m}$ pore size. The washing step was repeated for a minimum of five cycles. The filtered products were dried in a vacuum oven, and then the silanized GNPs were achieved.

\subsection{Fabrication of epoxy/GNP composites}

Different weights of raw or silanized GNPs (the weight ratio of raw and surface-modified GNPs to epoxy resin ranged from 0 to $10 \mathrm{wt} \%$ ) and $50 \mathrm{~mL}$ of acetone were added into a $50 \mathrm{~mL}$ beaker and the mixture was dispersed via ultrasonication for 30 $\min$. Then, $2 \mathrm{~g}$ of epoxy resin was added to the mixture and stirred for $24 \mathrm{~h}$ at $25^{\circ} \mathrm{C}$ in order to remove the acetone. After removing the acetone, the curing agent and accelerator were added to the mixture and it was vigorously stirred. Then, the acquired mixture was loaded into a custom Teflon mold. The composites were cured at $130^{\circ} \mathrm{C}$ for $1 \mathrm{~h}$ and $160^{\circ} \mathrm{C}$ for an additional $2 \mathrm{~h}$ in order to complete the curing cycle.

\subsection{Characterization}

In order to confirm the surface modification of the GNPs using the silane coupling agents (ETMOS, GPTS, and GPTMS), Fourier transform infrared spectroscopy (FT-IR, Bio-Rad FTS135, Brucker, USA) was used and thermogravimetric analyses (TGA, Q50, TA Instruments, USA) were conducted in a nitrogen atmosphere at a heating rate of $20^{\circ} \mathrm{C} / \mathrm{min}$. In order to investigate the morphology of the silanized GNPs, TEM (Philips CM 200, The Netherlands), scanning electron microscopy (SEM, S-4300, Hitachi), and energy dispersive X-ray spectroscopy (EDX, 6853H, Horiba) were used. All samples were sputter-coated with platinum prior to the SEM analyses. For the TEM analyses, all samples were placed on carbon-coated copper grids followed with vacuum drying.

The thermal conductivity of the GNP/epoxy composites was measured using a custom-made guarded heater meter, which is 
depicted in Fig. 1, as per the ASTM D5470 standard. All disktype specimens prepared in the PTFE mold were $1.2 \mathrm{~mm}$ thick with diameters of $15 \mathrm{~mm}$. In order to measure the thermal conductivity, the composites samples were prepared following the conditions reported elsewhere [23]. Furthermore, all samples were polished using Sic sandpaper purchased from R\&B Inc. (South Korea) and sand cloth wetted with $1 \mu \mathrm{m}$ of polycrystalline diamond suspension purchased from Allied High Tech Products, Inc. (USA) in order to smoothen the surfaces. This is an important step in order to obtain a homogeneous contact between the heat source and the surfaces of all samples. In order to achieve accurate thermal conductivities, the mean sample temperature was maintained to $45 \pm 1{ }^{\circ} \mathrm{C}$ through adjusting the heat flow $(\mathrm{Q})$. Furthermore, the temperature used for the calculation of the thermal conductivity was acquired when the temperatures measured at four thermocouples were stabilized within $\pm 0.1^{\circ} \mathrm{C}$ for 15 min [24]. In order to minimize the heat loss, the thermal conductivity measurement was conducted in a vacuum. The sample conductivity was calculated using following equation:

$$
\frac{Q}{A}=K_{s} \frac{\left(T_{S_{2}}-T_{S_{1}}\right)}{D}=K_{R} \frac{\left(T_{H_{2}}-T_{H_{1}}\right)+\left(T_{C_{2}}-T_{C_{1}}\right)}{L_{a}+L_{b}},
$$

where the symbols refer to the following: $Q=$ heat flow; $A=$ area of sample; $K_{\mathrm{s}}=$ sample conductivity; $K_{\mathrm{r}}=$ reference (copper) conductivity $(401 \mathrm{~W} / \mathrm{m} \mathrm{K}) ; T_{\mathrm{H} 1}, T_{\mathrm{H} 2}, T_{\mathrm{C} 2}$, and $T_{\mathrm{C} 1}=$ temperature at the thermocouples; $L_{\mathrm{a}}$ and $L_{\mathrm{b}}=$ distance between the lower and upper thermocouples; and $T \mathrm{~s}_{1}$ and $T \mathrm{~s}_{2}=$ the extrapolated temperatures at the surface of the sample. The electrical conductivity of the composites was measured using a high resistivity meter (Hiresta-UP, Mitsubishi Chemical Co., Japan) with a con-

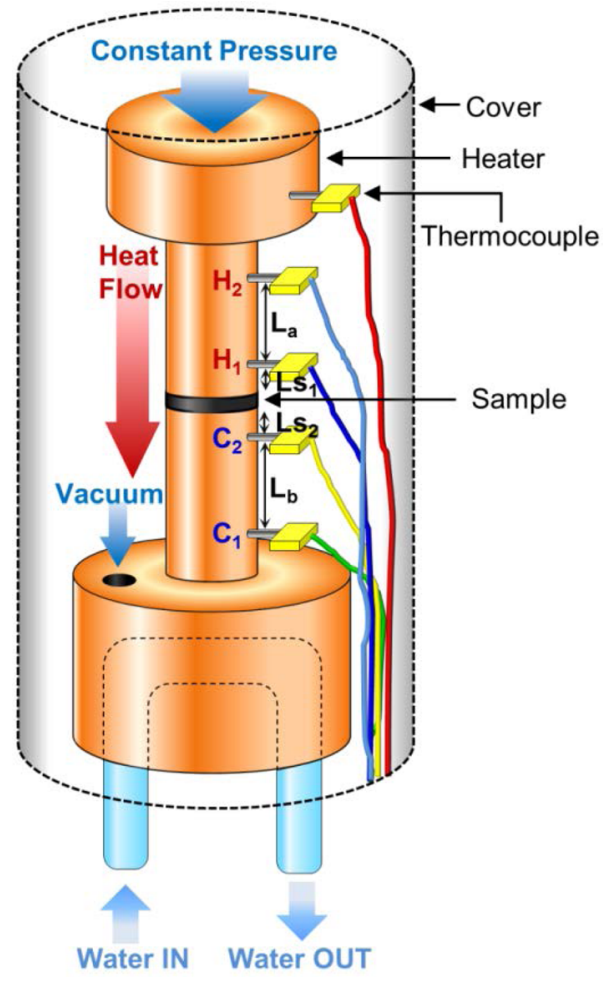

Fig. 1. Schematic of the custom-made guarded heater meter. stant voltage method. The dispersities of the raw and silanized GNPs in the polymer matrix were observed using the TEM and Turbiscan analyses. In order to conduct the Turbiscan analyses, $0.02 \mathrm{~g}$ of each GNP (raw and silanized GNP) and $20 \mathrm{~g}$ of $\mathrm{H}_{2} \mathrm{O}$ were added into a $50 \mathrm{~mL}$ vial and the mixture was dispersed using an ultrasonicator (SD-250H, Ujigae, South Korea) for 30 min. The detection head scanned the entire height of the sample acquiring the transmittance and backscattering data in steps of $30 \mathrm{~mm}$ every $1 \mathrm{~h}$ for $24 \mathrm{~h}$.

\section{Results and Discussion}

The chemical modifications of raw GNPs, hydroxylated GNPs, and three silanized GNPs were characterized using FTIR as illustrated in Fig. 2. In the FT-IR spectra, the characteristic peak at $2942.1 \mathrm{~cm}^{-1}$ of the samples indicated the aliphatic $\mathrm{CH}$ (-CH groups) deformation vibration, which is a basic structure of the raw, hydroxylated, and silanized GNPs. In particular, the spectrum of the hydroxylated GNPs was stronger than that of the raw and silanized GNPs at $3412 \mathrm{~cm}^{-1}$, which is related to the $\mathrm{C}-\mathrm{OH}$ stretching mode. This peak was attributed to the surface of the raw GNPs, which was modified by the mild oxidation process. Furthermore, the intensity of the hydroxyl peak (3412 $\mathrm{cm}^{-1}$ ) decreased significantly when the hydroxylated GNPs were silanized. In general, the silanized process was conducted through the chemical reaction between the trialkoxy groups of silane molecules and the hydroxyl groups on the substrates. The weak signal at $793 \mathrm{~cm}^{-1}$ confirmed the presence of the epoxy group on the silanized GNP [21]. Among the silanized GNPs, only the silanized GNPs treated with GPTMS had a peak from the epoxy group. For the silanized GNPs, two bands appeared at 1100 and $1400 \mathrm{~cm}^{-1}$, and these were attributed to the respective silane groups [25]. The silanized GNPs modified with GPTMS

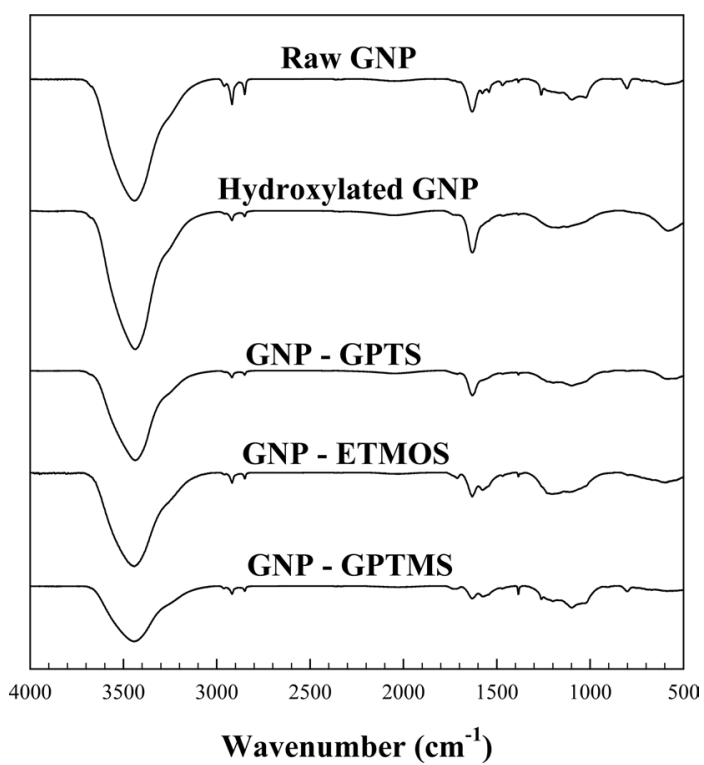

Fig. 2. Fourier transform infrared spectroscopy spectra of the raw graphene nanoplatelets (GNPs), hydroxylated GNPs, and silanized GNPs using GPTS, ETMOS, and GPTMS. GTPS: 3-glycidoxypropyltriethoxysilane, ETMOS: 2-(3,4-epoxycyclohexyl)-ethyltrimethoxysilane, GPTMS: 3-glycidoxypropyltrimethoxysilane. 


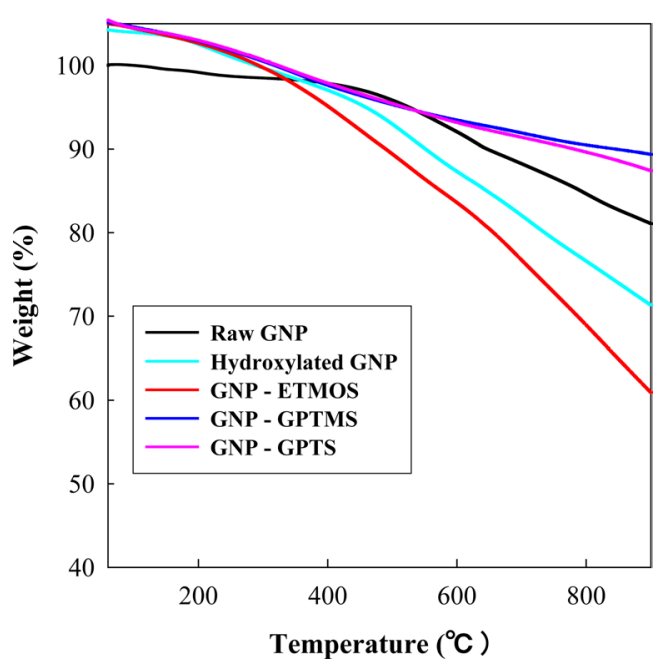

Fig. 3. Thermal gravity analyses data of the raw graphene nanoplatelets (GNPs), hydroxylated GNPs, and silanized GNPs using ETMOS, GPTMS and GPTS. ETMOS: 2-(3,4-epoxycyclohexyl)-ethyltrimethoxysilane, GPTMS: 3-glycidoxypropyltrimethoxysilane, GTPS: 3-glycidoxypropyltriethoxysilane.

had sharper peaks at 793,1100, and $1400 \mathrm{~cm}^{-1}$ in comparison with the other silanized GNPs.

TGA was performed for the quantitative analyses of the functionalization of the GNPs. The weight-loss thermograms of the raw, hydroxylated, and silanized GNPs are presented in Fig. 3. The weight of the hydroxylated GNPs decreased by $5 \%$ at $200^{\circ} \mathrm{C}-300^{\circ} \mathrm{C}$. Because the hydroxyl group was generally oxidized at $200^{\circ} \mathrm{C}-300^{\circ} \mathrm{C}[26]$, this demonstrates that the raw GNP surface was successfully hydroxylated. For the three silanized GNPs, the weight loss occurred at $300^{\circ} \mathrm{C}-450^{\circ} \mathrm{C}$, which is the temperature range where silane is decomposed. Furthermore, the thermal stability of the silanized GNPs with GPTMS and GPTS increased more than the raw and hydroxylated GNPs. When some carbon materials are well modified by the silane coupling agents, silica groups are generated that improve the thermal stability [27]. In Fig. 3, the silanized GNP with ETMOS exhibits a different thermal degradation pattern than the other silanized GNPs. The thermal stability of the silanized GNP with ETMOS was decreased more than the raw and hydroxylated GNPs. This result indicates that the silanization process using ETMOS results in defects in the GNP structure. From the FTIR and TGA results, the silane modifications of the GNPs were successfully conducted and GPTMS exhibited the best performance. From these analyses, GPTMS was selected for the following experiments.

The morphologies of the raw and silanized GNPs (using GPTMS) were investigated using SEM and TEM as depicted in Fig. 4. The surface of the raw GNPs was clear compared with that of the silanized GNPs. Unlike the raw GNPs, a mat-like morphology of the silanized GNPs was observed (Fig. 4b) and this resulted from the intermolecular hydrogen bonding or possible partial cross-linking via self-condensation of the silane between GNPs [2]. The resulting morphology of the silanized GNP was investigated using TEM in terms of the grafted silane molecules on the GNP surface. The difference in the contrast of the silanized GNPs in the TEM image (Fig. 4d) implies that the

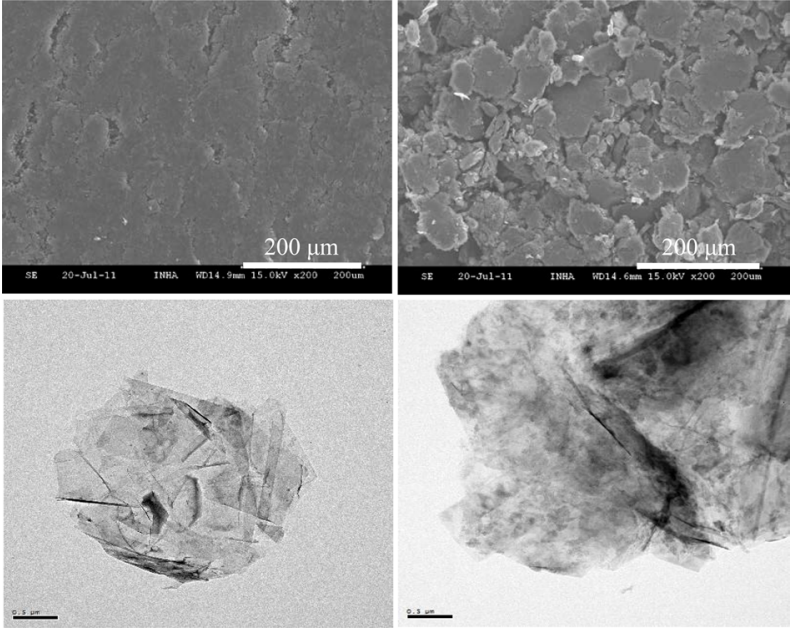

Fig. 4. Scanning electron microscopy and transmission electron microscopy images of the $(a, c)$ raw and $(b, d)$ silanized graphene nanoplatelets using 3-glycidoxypropyltrimethoxysilane.
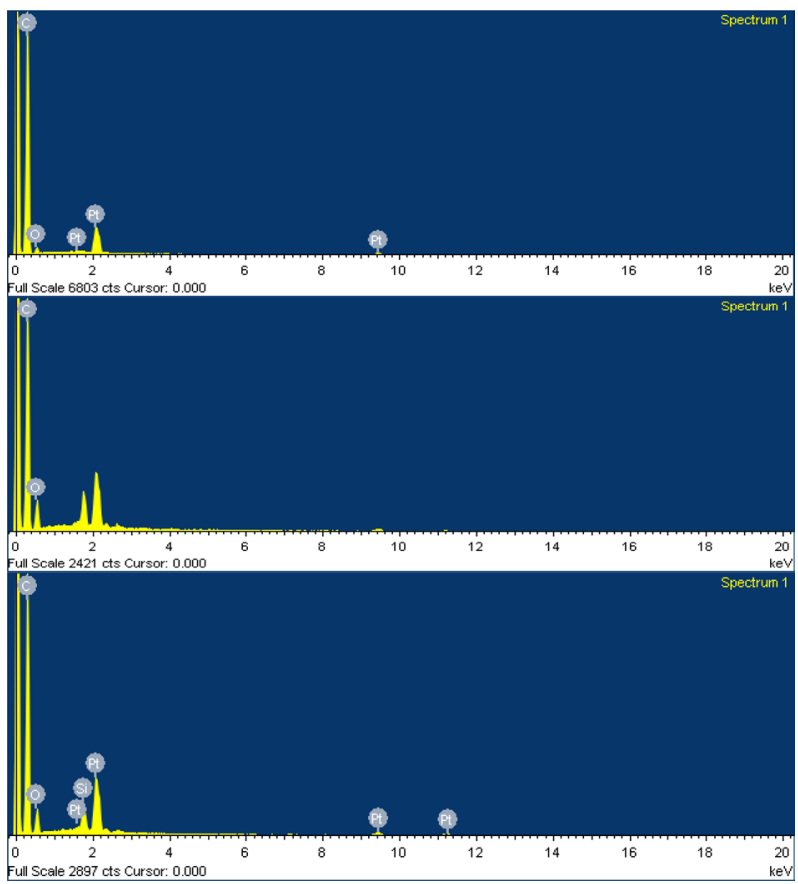

Fig 5. Energy dispersive $X$-ray spectroscopy spectrum of the raw graphene nanoplatelets (GNPs, top), hydroxylated GNPs (middle), and silanized GNPs (bottom).

silane molecules were attached to the GNP surface.

EDX was used to investigate the surface chemical state of the raw, hydroxylated, and silanized GNPs and to locate evidence of the silane coupling agent molecules on the modified GNPs as depicted in Fig. 5. The analyzed results are summarized in Table 1. For the raw and hydroxylated GNPs, the only existing elements were carbon and oxygen; however, the analyzed amounts of carbon and oxygen differed. The hydroxylated GNPs had greater amounts of oxygen than the raw GNPs due to the chemical oxidation process. More importantly, the silanized 
Table 1. EDX analyses of the raw GNPs, hydroxylated GNPs, and silanized GNPs

\begin{tabular}{ccccccc} 
& \multicolumn{2}{c}{ Raw GNPs } & \multicolumn{2}{c}{$\begin{array}{c}\text { Hydroxylated } \\
\text { GNPs }\end{array}$} & \multicolumn{2}{c}{$\begin{array}{c}\text { Silanized } \\
\text { GNPs }\end{array}$} \\
\cline { 2 - 7 } Element & $\begin{array}{c}\text { Atomic } \\
(\%)\end{array}$ & $\begin{array}{c}\text { Weight } \\
(\%)\end{array}$ & $\begin{array}{c}\text { Atomic } \\
(\%)\end{array}$ & $\begin{array}{c}\text { Weight } \\
(\%)\end{array}$ & $\begin{array}{c}\text { Atomic } \\
(\%)\end{array}$ & $\begin{array}{c}\text { Weight } \\
(\%)\end{array}$ \\
\hline $\mathrm{C}$ & 94.23 & 92.46 & 75.61 & 80.50 & 84.30 & 79.65 \\
\hline $\mathrm{O}$ & 5.77 & 7.54 & 24.39 & 19.50 & 15.08 & 18.98 \\
\hline $\mathrm{Si}$ & 0 & 0 & 0 & 0 & 0.62 & 1.37 \\
\hline
\end{tabular}

EDX: energy dispersive X-ray spectroscopy, GNPs: graphene nanoplatelets.

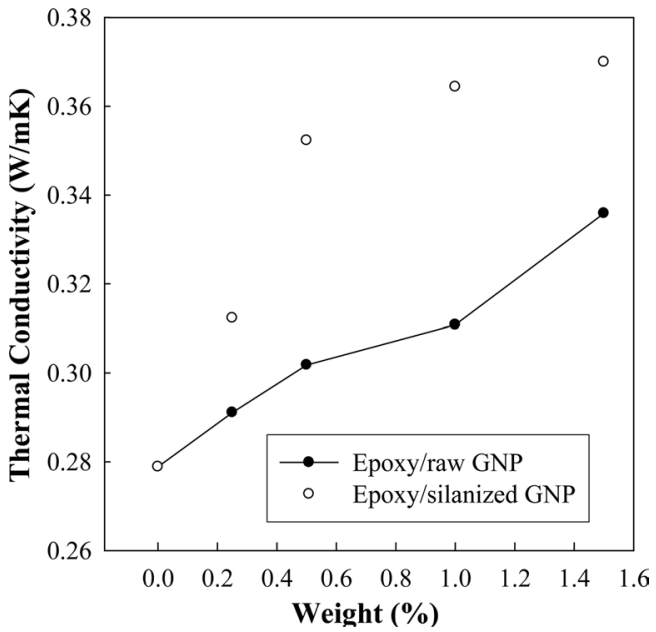

Fig. 6. Thermal conductivity of the epoxy/graphene nanoplatelet (GNP) and epoxy/silanized GNP composites.

GNPs had 0.62 at $\%$ of silicon, unlike the raw and hydroxylated GNPs, which is strong evidence of the chemical modification of GNPs using GPTMS

The effect of the surface modification of the GNPs on the thermal conductivity is presented in Fig. 6, which compares the thermal conductivity of the raw and silanized GNP/epoxy composites. The range of GNP loadings was from 0 to $1.5 \mathrm{wt} \%$. With increasing concentrations of raw GNPs, the thermal conductivity of the epoxy/raw GNP composites linearly increased from 0.28 to $0.33 \mathrm{~W} / \mathrm{mK}$. For the silanized GNP/epoxy composites, the thermal conductivity was higher than that of the raw GNP/ epoxy composites and it increased to $0.37 \mathrm{~W} / \mathrm{mK}$. This result might originate from the chemical structure of GPTMS having a terminal epoxy group, which has a good affinity with epoxy resin. This enhanced interfacial wettability decreases the contact resistance of the thermal conductivity between the GNPs and the matrix. Therefore, the thermal conductivity of the silanized GNP/epoxy composite was $12.1 \%$ higher than that of the raw GNP/epoxy composite at $1.5 \mathrm{wt} \%$ of GNP loading.

The aforementioned improvement of thermal conductivity due to the silane functionalization was expanded to the electrical conductivity in terms of the surface resistivity. The surface resistivity of the composites containing the raw and silanized

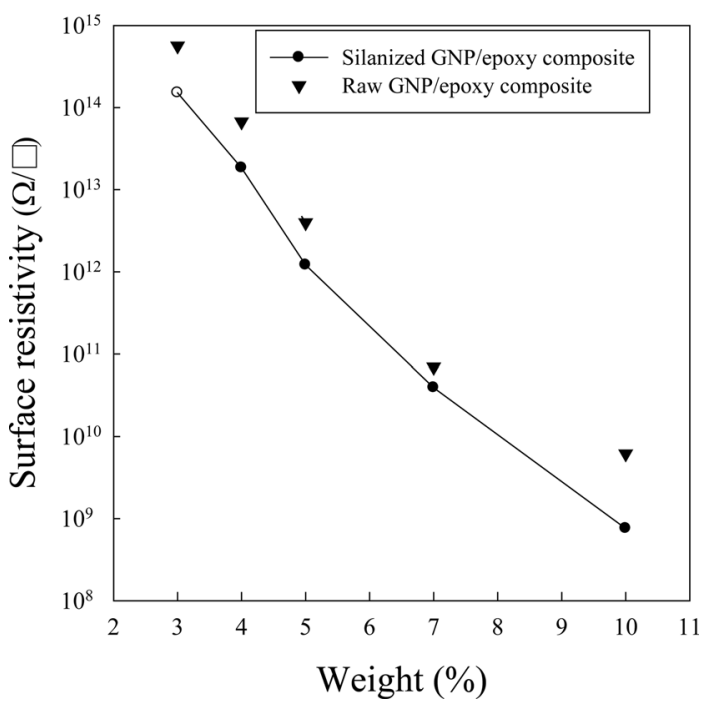

Fig. 7. Surface resistivity of the epoxy/raw graphene nanoplatelet (GNP) and epoxy/silanized GNP composites.
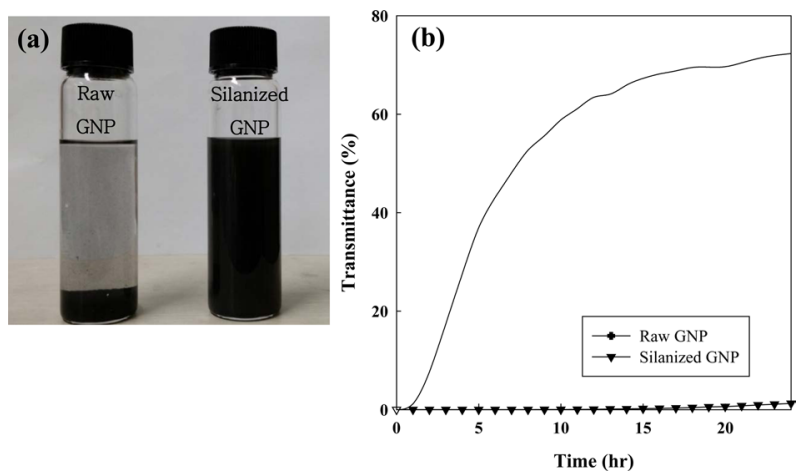

Fig. 8. (a) Photographs and (b) transmission rates with a dispersibility of 0.1 wt $\%$ raw and silanized graphene nanoplatelets (GNPs) in acetone.

GNPs is presented in Fig. 7. It should be noted that the surface resistivity of the composites was investigated from 3.0 $\mathrm{wt} \%$ GNP because the surface resistivity was immeasurably high below $3.0 \mathrm{wt} \%$ GNP. The incorporation of the raw GNP steadily decreased the resistivity from $5.64 \times 10^{14}$ to $5.17 \times 10^{9}$ $\Omega / \square$ when the GNP concentration increased from 3 to $10 \mathrm{wt} \%$. In the same manner, the surface resistivity of the epoxy/silanized GNP composites also linearly decreased from $1.51 \times 10^{14}$ to 5.17 $\times 10^{8} \Omega / \square$. Therefore, it is seen that the surface resistivity of the composites prepared using silanized GNPs was always lower than that of the raw GNP composites. However, this result differs from the previous results reported by Ma et al. [15]. In their results, the conductivity of the epoxy/silanized CNT composites was lower than that of the epoxy/raw CNT composites due to the silane molecules grafted on the CNT surface [22]. This difference might be correlated with the different dispersities between CNTs and graphene. Graphene has better dispersity in a polymer matrix than CNT due to its structure, as illustrated through the dispersion stability data (Fig. 8)

In order to verify the effect of the silanization, the disper- 


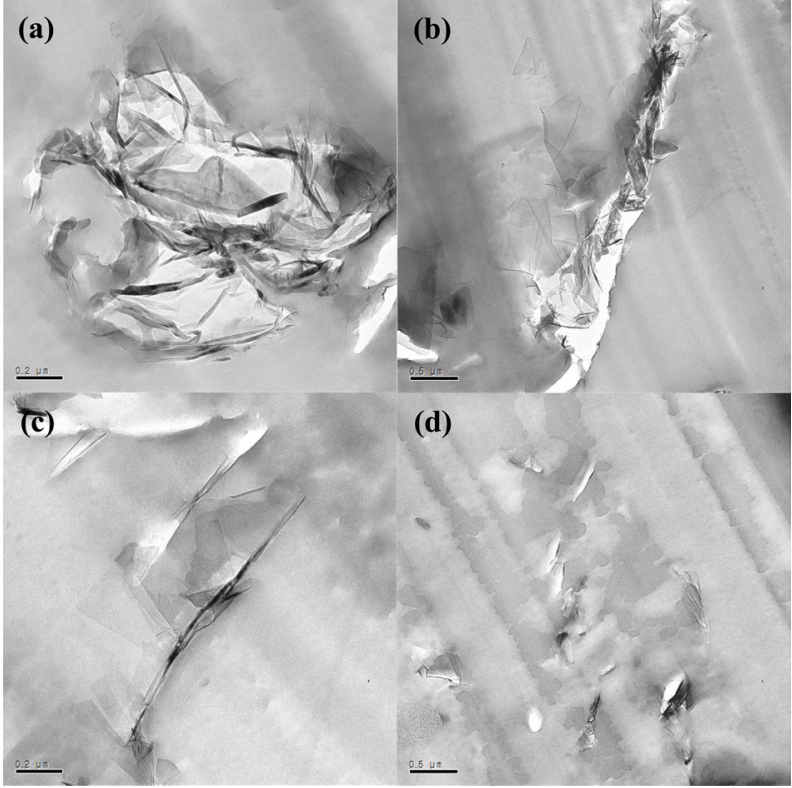

Fig. 9. Transmission electron microscopy images of epoxy composites incorporating $(a, b)$ raw and $(c, d)$ silanized graphene nanoplatelets.

sity of $0.1 \mathrm{wt} \%$ raw and silanized GNPs/acetone suspension is depicted in Fig. 8. For the sample preparation, $0.02 \mathrm{~g}$ of GNPs and $20 \mathrm{~g}$ of acetone were added in a $50 \mathrm{~mL}$ vial, and the mixture was dispersed using a bath sonicator for $30 \mathrm{~min}$. As seen in Fig. 8a, most raw GNPs were sedimented after $12 \mathrm{~h}$; however, a good dispersion state was maintained for the silanized GNPs in acetone. For more qualitative analyses, the variation of the transmittance of light through the GNPs/acetone suspension was monitored using Turbiscan (Fig. 8b). It should be noted that the increase in the transmittance indicates that the suspension becomes transparent due to the sedimentation of the suspended substances. In Fig. 8b, the transmittance of the raw GNP/acetone suspension rapidly increased within $10 \mathrm{~h}$ and progressively increased with time, which implies that the raw GNPs agglomerate and settle in the initial stages and that sedimentation continuously occurs. In contrast, the transmittance of the silanzied GNP/acetone suspension does not change for $24 \mathrm{~h}$, which proves that silanized GNPs have significantly enhanced colloidal stability in acetone. Because acetone was used for the preparation of the GNP/epoxy composites, it is expected that silanized GNPs would have a more uniform dispersion in an epoxy matrix.

TEM images of the ultramicrotomed cross-sections of the raw and silanized GNP/epoxy composites are presented in Fig. 9. These microphotographs illustrate that the silanized GNPs (Fig. 9b) were more uniformly dispersed in the epoxy matrix than the raw GNPs (Fig. 9a). This might result from the enhanced interfacial interaction between the terminal epoxy group in the silane coupling agent and epoxy matrix, and also from the improved colloidal dispersion of the silanized GNPs in acetone during the composite preparation step. Finally, the introduction of an appropriate silane coupling agent on the surface of GNPs improves the thermal conductivity and surface resistivity due to the interfacial affinity between the GNPs and matrix and the enhanced dispersion in the matrix.

\section{Conclusion}

In this study, the effects of the silanization of GNPs were investigated related to the thermal and electrical conductivities. Three silane coupling agents (ETMOS, GPTS, and GPTMS) were used for the surface modification of the GNPs. Because GPTMS exhibited better modification abilities, it was selected for the fabrication of the epoxy/silanized GNPs. In order to demonstrate the effects of the silanization, the thermal and surface resistivities of the epoxy/raw and silanized composites were measured. The epoxy/silanized GNP composite exhibited higher thermal conductivity and lower electrical resistivity than the epoxy/raw GNP composite, which resulted from the improved dispersion uniformity of the GNPs in the epoxy. The dispersity characterized using TEM revealed that the silanized GNPs were more uniformly dispersed in the epoxy matrix than the raw GNPs. These results indicate that silane molecules bearing epoxy functionality have a promising effect on the dispersion of GNPs in epoxy matrices.

\section{Acknowledgments}

This study was supported by the Regional Innovation Center for Environmental Technology of Thermal Plasma (RICETTP) at Inha University designated by MOCIE (2014) and a National Research Foundation of Korea (grant no.: 2013R1A2A2A04013913).

\section{References}

[1] Zheng C, Fan Z, Wei T, Luo G. Temperature dependence of the conductivity behavior of graphite nanoplatelet-filled epoxy resin composites. J Appl Polym Sci, 113, 1515 (2009). http://dx.doi org/10.1002/app.30009.

[2] Zhu J, Peng H, Rodriguez-Macias F, Margrave JL, Khabashesku VN, Imam AM, Lozano K, Barrera EV. Reinforcing epoxy polymer composites through covalent integration of functionalized nanotubes. Adv Funct Mater, 14, 643 (2004). http://dx.doi. org/10.1002/adfm.200305162.

[3] Sandler J, Shaffer MSP, Prasse T, Bauhofer W, Schulte K, Windle AH. Development of a dispersion process for carbon nanotubes in an epoxy matrix and the resulting electrical properties. Polymer, 40, 5967 (1999). http://dx.doi.org/10.1016/S0032-3861(99)001664.

[4] Fox RT, Wani V, Howard KE, Bogle A, Kempel L. Conductive polymer composite materials and their utility in electromagnetic shielding applications. J Appl Polym Sci, 107, 2558 (2008). http:// dx.doi.org/10.1002/app.27317.

[5] Moisala A, Li Q, Kinloch IA, Windle AH. Thermal and electrical conductivity of single- and multi-walled carbon nanotube-epoxy composites. Compos Sci Technol, 66, 1285 (2006). http://dx.doi. org/10.1016/j.compscitech.2005.10.016.

[6] Pumera M, Merkoçi A, Alegret S. Carbon nanotube-epoxy composites for electrochemical sensing. Sens Actuators B, 113, 617 (2006). http://dx.doi.org/10.1016/j.snb.2005.07.010

[7] Yu A, Ramesh P, Sun X, Bekyarova E, Itkis ME, Haddon RC 
Enhanced thermal conductivity in a hybrid graphite nanoplatelet: carbon nanotube filler for epoxy composites. Adv Mater, 20, 4740 (2008). http://dx.doi.org/10.1002/adma.200800401.

[8] Hindermann-Bischoff M, Ehrburger-Dolle F. Electrical conductivity of carbon black-polyethylene composites: experimental evidence of the change of cluster connectivity in the PTC effect. Carbon, 39, 375 (2001). http://dx.doi.org/10.1016/S00086223(00)00130-5.

[9] Wang S, Tambraparni M, Qiu J, Tipton J, Dean D. Thermal expansion of graphene composites. Macromolecules, 42, 5251 (2009) http://dx.doi.org/10.1021/ma900631c.

[10] Ghosh G, Calizo I, Teweldebrhan D, Pokatilov EP, Nika DL, Balandin AA, Bao W, Miao F, Lau CN. Extremely high thermal conductivity of graphene: prospects for thermal management applications in nanoelectronic circuits. Appl Phys Lett, 92, 151911 (2008). http://dx.doi.org/10.1063/1.2907977.

[11] Xie SH, Liu YY, Li JY. Comparison of the effective conductivity between composites reinforced by graphene nanosheets and carbon nanotubes. Appl Phys Lett, 92, 243121 (2008). http://dx.doi. org/10.1063/1.2949074.

[12] Yu A, Ramesh P, Itkis ME, Bekyarova E, Haddon RC. Graphite nanoplatelet: epoxy composite thermal interface materials. J Phys Chem C, 111, 7565 (2007). http://dx.doi.org/10.1021/jp071761s.

[13] Biercuk MJ, Llaguno MC, Radosavljevic M, Hyun JK, Johnson AT, Fischer JE. Carbon nanotube composites for thermal management. Appl Phys Lett, 80, 2767 (2002). http://dx.doi. org/10.1063/1.1469696.

[14] Putnam SA, Cahill DG, Ash BJ, Schadler LS. High-precision thermal conductivity measurements as a probe of polymer/nanoparticle interfaces. J Appl Phys, 94, 6785 (2003). http://dx.doi. org/10.1063/1.1619202.

[15] Ma PC, Kim JK, Tang BZ. Functionalization of carbon nanotubes using a silane coupling agent. Carbon, 44, 3232 (2006).

[16] Ganguli S, Roy AK, Anderson DP. Improved thermal conductivity for chemically functionalized exfoliated graphite/epoxy composites. Carbon, 46, 806 (2008). http://dx.doi.org/10.1016/j.carbon.2008.02.008.

[17] Park OK, Jeevananda T, Kim NH, Kim SI, Lee JH. Effects of surface modification on the dispersion and electrical conductivity of carbon nanotube/polyaniline composites. Scripta Mater, 60, 551
(2009). http://dx.doi.org/10.1016/j.scriptamat.2008.12.005.

[18] Zhao W, Song C, Pehrsson PE. Water-soluble and optically pH-sensitive single-walled carbon nanotubes from surface modification. J Am Chem Soc, 124, 12418 (2002). http://dx.doi.org/10.1021/ ja027861n.

[19] Kim JA, Seong DG, Kang TJ, Youn JR. Effects of surface modification on rheological and mechanical properties of CNT/epoxy composites. Carbon, 44, 1898 (2006). http://dx.doi.org/10.1016/j. carbon.2006.02.026

[20] Vast L, Philippin G, Destrée A, Moreau N, Fonseca A, Nagy JB, Delhalle J, Mekhalif Z. Chemical functionalization by a fluorinated trichlorosilane of multi-walled carbon nanotubes. Nanotechnology, 15, 781 (2004). http://dx.doi.org/10.1088/0957-4484/15/7/011

[21] Deng Y, Deng C, Yang D, Wang C, Fu S, Zhang X. Preparation, characterization and application of magnetic silica nanoparticle functionalized multi-walled carbon nanotubes. Chem Commun, 5548 (2005). http://dx.doi.org/10.1039/B511683J.http://dx.doi org/10.1016/j.carbon.2006.06.032.

[22] Ma PC, Kim JK, Tang BZ. Effects of silane functionalization on the properties of carbon nanotube/epoxy nanocomposites. Compos Sci Technol, 67, 2965 (2007). http://dx.doi.org/10.1016/j.compscitech.2007.05.006.

[23] Sim LC, Ramanan SR, Ismail H, Seetharamu KN, Goh TJ. Thermal characterization of $\mathrm{Al}_{2} \mathrm{O}_{3}$ and $\mathrm{ZnO}$ reinforced silicone rubber as thermal pads for heat dissipation purposes. Thermochim Acta, 430, 155 (2005). http://dx.doi.org/10.1016/j.tca.2004.12.024.

[24] Liu CH, Huang H, Wu Y, Fan SS. Thermal conductivity improvement of silicone elastomer with carbon nanotube loading. Appl Phys Lett, 84, 4248 (2004). http://dx.doi.org/10.1063/1.1756680.

[25] Tanaka S, Chao Y, Araki S, Miyake Y. Pervaporation characteristics of pore-filling PDMS/PMHS membranes for recovery of ethylacetate from aqueous solution. J Membr Sci, 348, 383 (2010). http://dx.doi.org/10.1016/j.memsci.2009.11.033.

[26] Lee MY, Park WH, Lenz RW. Hydrophilic bacterial polyesters modified with pendant hydroxyl groups. Polymer, 41, 1703 (2000). http://dx.doi.org/10.1016/S0032-3861(99)00347-X.

[27] Dhawade P, Jagtap R. Comparative study of physical and thermal properties of chitosan-silica hybrid coatings prepared by sol-gel method. Der Chem Sin, 3, 589 (2012). 